\title{
The response of areal snow cover to climate change in a snowmelt-runoff model
}

\author{
A. RANGO \\ Hydrology Laboratory, U.S. Department of Agriculture, Beltsville, MD 20901, U.S.A.
}

\begin{abstract}
The cryosphere is represented in some hydrological models by the areal extent of snow cover, a variable that has been operationally available in recent years through remote sensing. In particular, the snowmelt-runoff model (SRM) requires the remotely sensed snow-cover extent as a major input variable. The SRM is well-suited for simulating the hydrological response of a basin to hypothetical climate change because it is a non-calibrated model. In order to run the SRM in a climate-change mode, the response of the areal snow cover to a change in climate is critical, and must be calculated as a function of elevation, precipitation, temperature, and snow-water equivalent. For the snowmelt-runoff season, the effect of climate change on conditions in the winter months has a major influence. In a warmer climate, winter may experience more rain vs snow events, and more periods of winter snowmelt that reduce the snow water equivalent present in the basin at the beginning of spring snowmelt. As a result, the spring snowmelt runoff under conditions of climate warming will be affected not only by different temperatures and precipitation, but also by a different snow cover with a changed depletion rate. A new radiation-based version of the SRM is under development that will also take changes in cloudiness and humidity into account, making climate-change studies of the cryosphere even more physically based.
\end{abstract}

\section{INTRODUGTION}

The areal extent of snow cover is important in both climatology and hydrology. Because snow is so different from other natural surfaces, it can have an important effect on climate. In the Northern Hemisphere in winter, over $50 \%$ of the land surface can be covered by snow (Foster and Rango, 1982), which can have a major influence on weather systems and storm tracks. In hydrology, there are mountainous areas that receive more than $90 \%$ of total streamflow from snowmelt (Goodell, 1966). This snowmelt-fed runoff makes up about $33 \%$ of worldwide irrigation waters, and in some locations it is responsible for $100 \%$ of the irrigation water supply (Steppuhn, 1981).

Snowmelt-runoff models are commonly used as tools in evaluating the effects of climate change (Cooley, 1990; Gleick, 1989; Kite, 1993; Pangoulia, 1991; Van Katwijk and others, 1993). The areal extent of snow cover is explicitly required by a few models. Any models that operate on an areal basis require some sort of information on areal extent of snow cover, explicit or implicit, because it is necessary to know where, in the basin of interest, to apply snowmelt algorithms and rain-on-snow algorithms. Some models calculate the snow water equivalent accumulation using precipitation and temperature measurements, and from this calculated snow water equivalent derive a snow-cover extent value. The main difficulty here is that the measurement of precipitation in mountain regions is seriously flawed. Major problems with precipitation-gauge catch deficits, inadequate numbers of gauges, and extrapolation to higher elevations are known to exist. Rather than calculate snow-cover extent with flawed data, it is much preferable simply to use remote sensing actually to measure the exist- ing snow-cover extent, and use this information in the model. Such measurements are now available operationally in certain countries (Carroll, 1995).

The snowmelt-runoff model (SRM), which has widely been used and documented (Martinec and others, 1994; Rango, 1992), requires the measured snow-covered area as one of its driving input variables. In the simulation mode, the SRM can directly accept measured remotely sensed snow-cover data. In the forecasting or climate-change modes, the SRM must first calculate the snow-cover extent in the future climate using previously derived relationships between snow cover, temperature, precipitation and snow water equivalent. In the forecasting mode, when actual snow-cover measurements are obtained, these relationships can be used to update the calculations. In the climatechange mode, once the projected future snow-cover extent is available, the SRM can then be run under the new climate conditions, and compared with the existing or current climate. Climate scenarios that include changes in temperature and precipitation can be accommodated. Because the SRM is a non-calibrated model, it is appropriate for use in this climate-change mode. The World Meteorological Organization (Becker and Serban, 1990) has pointed out that it is not appropriate to use calibrated models for climate-change evaluations, although many investigators have done so.

The method outlined for use here with the SRM should be of value for application with any snowmelt-runoff model that uses snow-cover extent data as an input or output variable. It appears that an increasing number of models are employing snow-cover patterns to assist in the calculation of runoff. Leavesley and Stannard (1990) have begun to in- 
corporate snow cover into the Precipitation Runoff Modeling System (PRMS) model, and Brandt and Bergström (1994) report on experiments to input satellite-derived snow-cover data to the widely-used Swedish HBV model. Brandt and Bergström (1994) indicate that the satellite data will become more useful when the snowmelt-runoff models become more widely distributed in geographical terms. The Canadian model SLURP (Kite, 1995) employs geographical information systems to facilitate the input of satellite-derived snow-cover data to calculate snowmelt runoff from large basins. Kirnbauer and others (1994) postulate that snow-cover depletion patterns are vastly superior to runoff for evaluating performance of distributed snow models. This use of snow-cover patterns, as obtained from aerial photography as an output variable, was demonstrated by Blöschl and others (1991).

\section{RESPONSE OF SNOW COVER TO A CLIMATE CHANGE}

All models used to evaluate the hydrologic effects of climate change must make some allowance for snow cover in the basin, so that it is adjusted to the new climate conditions. If no adjustment is made, then erroneous snowmelt-runoff calculations will result. The snow-cover change that will result under new climate conditions depends on the topographical characteristics of the basin and the temperature, precipitation and snow water equivalent associated with the new climate. The snow-cover characteristics in the basin at the beginning of the snowmelt season depend heavily on how the climate changes during the preceding winter season. Although in reality, the amount of precipitation and perhaps its distribution will be likely to change in the new climate, the simplest example assumes that the precipitation remains the same for purposes of demonstration. Precipitation changes can be easily added later, and will be generally within $\pm 20 \%$ of the current levels (Nash and Gleick, 1993). In general, a warmer climate is expected to prevail during both the snowmelt season and the winter-accumulation season.

Two major changes take place in winter as temperatures increase. First, more rain, as opposed to snow events, takes place, resulting in more immediate runoff and less snow accumulation. Second, the warmer temperatures cause more snowmelt and runoff from the basin during the winter months. As a result, the snowpack reserves at the beginning of the snowmelt season are reduced, and input to snowmelt models must reflect this.

The following steps are taken in calculating the effect of increased temperature on snow accumulation and depletion. First, the decrease of the basin snow water equivalent present at the beginning of the snowmelt season (usually 1 April) is computed by comparing the simulated winter runoff (October-March) before and after a climate change (temperature increase) during these months. The decrease of snow water equivalent at the beginning of the snowmelt season on 1 April after the climate change is equal to the difference in the total winter inputs to runoff. Second, the conventional zonal snow-cover depletion curves, which are obtained from satellite remote sensing, are converted to modified depletion curves $\left(\mathrm{MDC}_{\mathrm{INCL}}, \mathrm{MDC}_{\mathrm{EXCL}}\right.$ ) (Martinec, 1985). As has been explained elsewhere, the area beneath the $\mathrm{MDC}_{\mathrm{EXCL}}$ indicates the average water equivalent (HW) of the snow cover on 1 April (Martinec and Rango, 1987). Third, in order to take into account the climate-change effect of the preceding winter half-year, the $\mathrm{MDC}_{\mathrm{EXCL}}$ must omit any snow that has melted as a result of the new warmer winter temperatures.

Figure 1 shows the curves that result from the lowest elevation zone (2432-2926 m a.s.l.) for the Rio Grande basin, Colorado $\left(3419 \mathrm{~km}^{2}\right)$ in 1979 for a $+4^{\circ} \mathrm{C}$ warming, which is at the lower range of maximum warming in this area as summarized by Nash and Gleick (1993). When the amount of winter melt attributed to the $+4 \mathrm{C}$ is cut off the $\mathrm{MDC}_{\mathrm{EXCL}}$, the remaining modified-depletion curve is termed winter adjusted or $\mathrm{MDC}_{\text {EXCLwA. In Figure 1, it is }}$ apparent that a major reduction, from $58.1 \mathrm{~cm}$ to $20.4 \mathrm{~cm}$ in the HW present at the beginning of snowmelt has occurred. Fourth, the MDC ExcLws is used to derive the winter-adjusted modified depletion curve for the new climate ( $\mathrm{MDC}_{\mathrm{CI} \text { III }}$ ) by the addition of any snowfalls that survive after the beginning of the melt season in the new warmer climate (i.e. precipitation events that occur at a temperature less than the critical temperature [temperature that separates rain from snow events] after the $+4^{\circ} \mathrm{C}$ warming has been imposed). Figure 2 shows that, because some snowfalls occurred at low enough temperatures to remain as snow and not be converted to rainfalls, the MDC CLIM wa $_{\text {in }}$ is slightly higher than the $M D_{\text {EXCLwA. Finally, these }}$ MDC $_{\text {CLIM WA }}$ curves are converted back into the conventional-depletion curves in the new climate adjusted for the winter effect, $\left(\mathrm{CDC}_{\text {(IIIMINA }}\right)$.

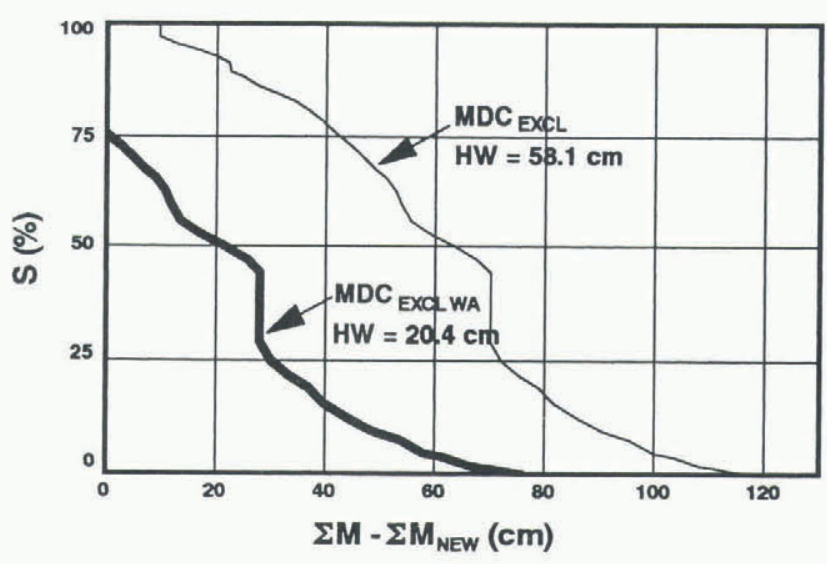

\begin{abstract}
Fig. 1. Modified depletion curves for zone A of the Rio Grande basin with new snow excluded. The area below $M D C_{E X X L}$ indicales the snow-water equivalent on 1 April 1979; the area below $M D C_{E X C L \text {. }}$ indicates the snow-water equivalent on 1 April 1979 with a temperature increase of $+4^{\circ} \mathrm{C}$.
\end{abstract}

Figure 3 shows the original CDC and the $\mathrm{CDC}_{\mathrm{CLIM}}$ wa as a result of $\mathrm{a}+4 \mathrm{C}$ for each zone of the Rio Grande basin in 1979. Figure 4 is a conceptual comparison showing the resulting $\mathrm{CDC}_{\mathrm{CLIM}}$ if the effect of the winter adjustment was not considered on a hypothetical basin. Too much snow

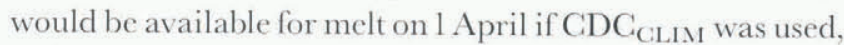
and an over-abundance of snowmelt runoff would occur. If this erroneous over-prediction was not realized, planning to cope with the climate-change effects would be in considerable error. 


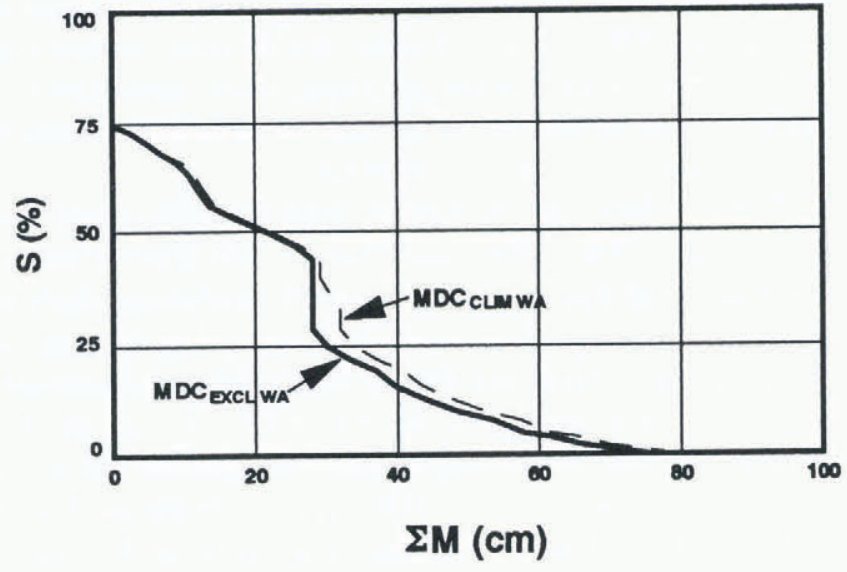

Fig. 2. Winter adjusted modified-depletion curves $M D C_{E X C L W A}$ and $M D C_{C L I M W A}$ (remaining snowfalls added) for a temperature increase of $+4^{\circ}$ C in zone $A$ in 1979.

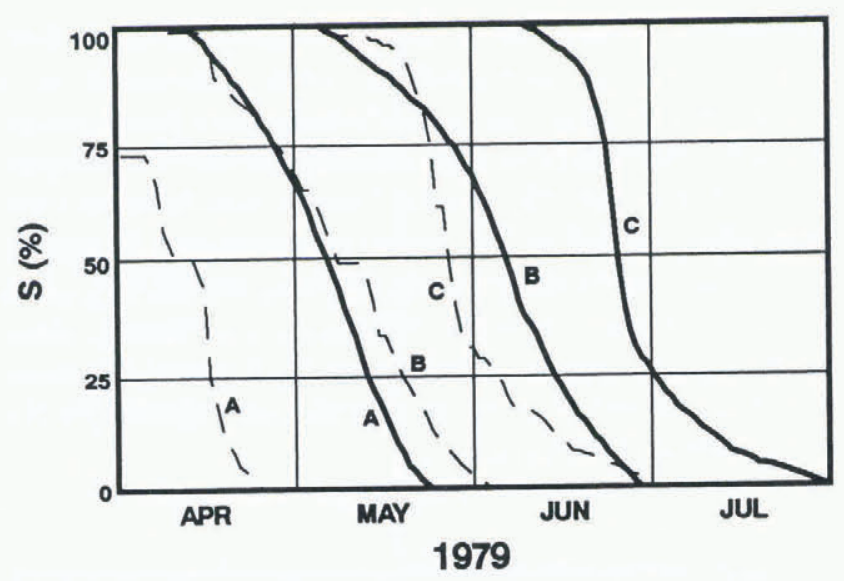

Fig. 3. Conventional depletion curves (CDC) in zones $A, B$ and $C$ of the Rio Grande basin in 1979, and resulting climatewinter adjusted conventional depletion curves $\left(C D C_{C L I M}\right.$ WA).

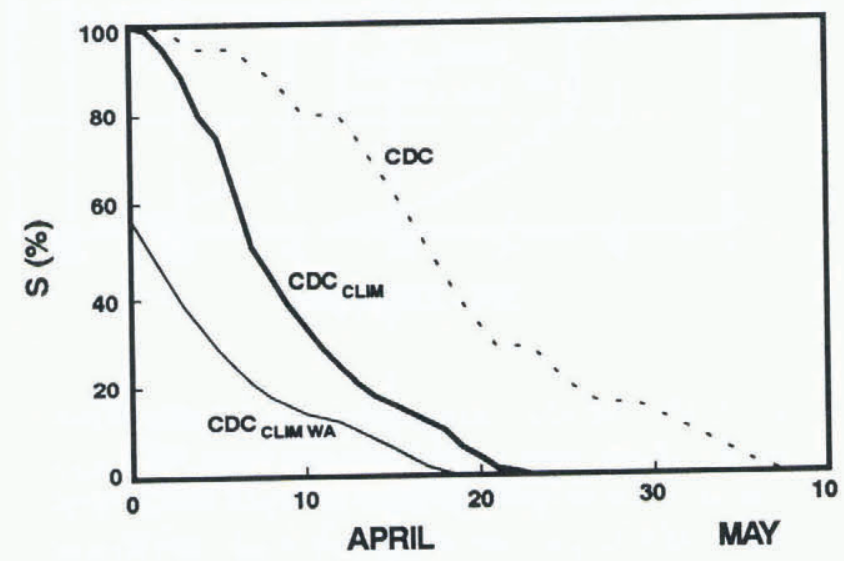

Fig. 4. Original CDC (present climate) in a hypothetical basin and the $C D C_{C L I M W A}$ resulting from a temperature increase of $+4^{\circ} \mathrm{C}$ in the entire hydrological year. The conventional depletion curve without the winter half-year considered $\left(C D C_{C L I M}\right)$ is shown.

\section{HYDROLOGICAL RESPONSE TO A CHANGED SNOW COVER}

Once climate scenarios of changed temperature (and precipitation) are available, SRM will automatically change the snow cover in a given year in consideration of these new climate variables. With the new snow cover derived as a function of the winter adjustment, the year-round runoff under conditions of climate change can be produced. For the Rio Grande basin, above-normal (1979), below-normal (1977), and near-normal (1976) runoff years were selected for comparison. $\mathrm{A}+4^{\circ} \mathrm{C}$ temperature increase with precipitation remaining the same was retained for these runs, although an infinite variety of changes is possible. Figure 5 shows the new hydrograph under conditions of climate change for 1976.

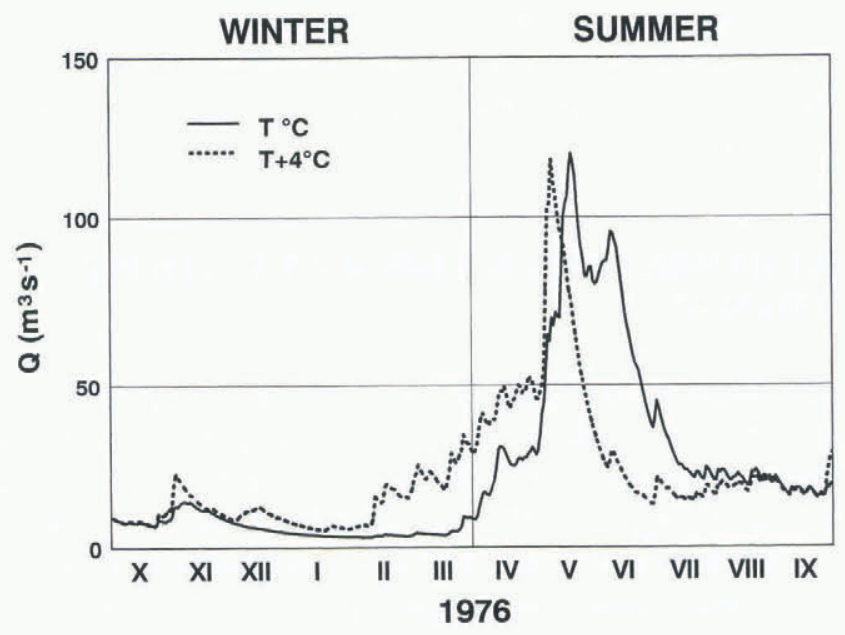

Fig. 5. Simulated runoff in the Rio Grande basin for an average hydrological year (1976) computed for present temperatures, and for a temperature increase of $+4^{\circ} \mathrm{C}$.

It is apparent from Figure 5 and the other hydrographs, that the spring runoff peaks occur anywhere from two to four weeks earlier, and, generally, the peak is about the same magnitude or slightly higher. The month of April receives large increases in runoff, which may require major adaptation in the operating rules for the regulation of water storage reservoirs. June and July experience major decreases in flow, which may further exacerbate the already existing competition for a limited water supply.

The winter half-year (October-March) experiences an increased proportion of the total annual runoff because of the climate-change redistribution of flow. Figure 6 presents the relative proportion of flow divided between the winter

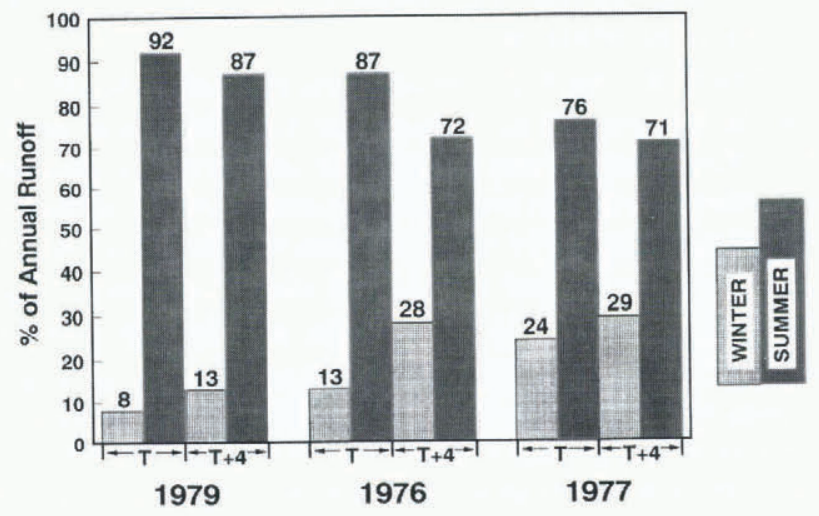

Fig. 6. Proportions of winter and summer runoff in selected years in the present climate $(T)$ and in a warmer climate $\left(T+4^{\circ} C\right)$ for the Rio Grande basin. 
months and the summer months (April-September) for the Rio Grande basin. The largest change is evident in the nearnormal year (1976). The extreme years do not experience as large a percentage change, but in the wet year (1979) the volume change is large, whereas in the dry year (1977) the already existing drought conditions are intensified.

In all of these year-round climate-change runs, physically based model parameters such as the degree-day coefficient and the runoff coefficient are shifted to approximate the earlier advance of the seasons and snowmelt (Van Katwijk and others, 1993). Such logical changes in model parameters need to be made by all models if they are to be used to evaluate the effects of climate change. Thus far, these parameter effects have generally been overlooked.

\section{ADDITION OF A RADIATION MELT COMPONENT TO THE SRM}

Despite the past success with the SRM in both simulation and forecasting, there are significant drawbacks to a degree-day model. In order to make the SRM more physically based, and to make it more compatible with additional variables that may be subject to climate change, a new version of the SRM incorporating net surface radiation is under development (Kustas and others, 1994; Brubaker and others, 1996; Brubaker and Rango, 1996). Depending on data availability and user preference, the user would be able to choose between the simple temperature index version and the slightly more complex temperature and radiation version. The basic equation for calculating snowmelt in the original SRM is:

$$
M=a T_{\mathrm{d}}
$$

where $T_{\mathrm{d}}\left({ }^{\circ} \mathrm{C}\right)$ is the degree-day index and $a\left(\mathrm{~cm}^{\circ} \mathrm{C}^{-1} \mathrm{~d}^{-1}\right)$ is the degree-day coefficient. In the radiation SRM version, Equation [1] is expanded to:

$$
M=a_{\mathrm{r}} T_{\mathrm{d}}+m_{\mathrm{Q}} R_{\mathrm{d}}
$$

where $a_{\mathrm{r}}\left(\mathrm{cm}^{\circ} \mathrm{C}^{-1} \mathrm{~d}^{-1}\right)$ is a restricted degree-day coefficient, $m_{\mathrm{Q}}\left[\left(\mathrm{cm} \mathrm{d}^{-1}\right)\left(\mathrm{W} \mathrm{m}^{2}\right)^{-1}\right]$ is a physical constant converting energy to water mass or depth, and $R_{d}\left(\mathrm{~W} \mathrm{~m}^{-2}\right)$ is the net radiation index. An immediate advantage of the radiationbased version is that the $a_{\mathrm{r}}$ is not as variable as the simple $a$ and is easier for the user to estimate. The net radiation version can use actual radiation measurements, or can calculate the net radiation based on meteorological data and topography. As a result, in addition to altered temperature and precipitation in a hypothetically changed climate, this radiation-based version can account for changes in cloudiness and humidity that affect the net radiation received at the snow surface.

In the original SRM, the basin is divided into elevation zones for input of remotely sensed snow-covered area. In the radiation-based SRM, the basin is further subdivided into aspect/elevation zones to account for differences in solar radiation received. The integrated use of remote sensing and geographical information systems is necessary (Rango and Baumgartner, 1996).

To illustrate some of the possibilities of the radiation version of the SRM, the model was tested on the Dischma basin $\left(43.3 \mathrm{~km}^{2}\right)$ in Switzerland. Figure 7 shows a simulated climate-change scenario based on the 1977 melt season. In this case, we have a $+3^{\circ} \mathrm{C}$ warming with clouds unchanged (from 1977 observations), optically thinner clouds, and opti-

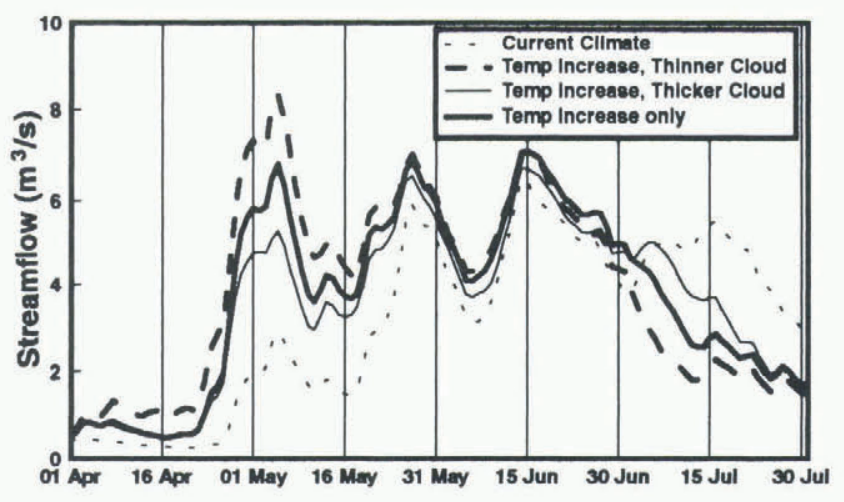

\section{Fig. 7. Simulated climate-change scenarios based on the 1977 melt season in the Dischma basin for a warmer climate $\left(T+3^{\circ} \mathrm{C}\right)$, with optically-thinner, optically-thicker, and un- changed clouds.}

cally thicker clouds. (In this case humidity remains the same, although it could also be changed in other scenarios.) The new model is sensitive to cloud optical thickness. As expected, optically thinner clouds allow more solar energy to reach the surface, further increasing the snowmelt during the shifted peak period earlier in the snowmelt season. The thicker clouds partially offset the effect of the increased temperature and resultant melt. Because improved satellite observations of clouds are becoming available (Simpson and Gobat, 1995), such model improvements should be useful in the future. Additionally, a new generation of cloud imagers associated with the Clouds and the Earth's Radiant Energy System (CERES) will be onboard NASA's satellites starting in 1997 (Wielicki and others, 1996), and should provide more information for the improved SRM. It is hoped that general circulation model (GCM) scenarios of climate change will also include improved cloud information for the climate-change evaluations. Research in mesoscale models and climate-change scenarios may be even better suited for individual basins than GCM scenarios.

\section{CONCLUSIONS}

When snowmelt-runoff models are used to evaluate hypothetical climate-change scenarios, the areal extent of snow cover is an important variable for all models. At a minimum, models should know where the snow is located in the new climate, so that snowmelt and rain-on-snow algorithms can be applied to the relevant areas of a basin. The change of areal snow extent is even more important to the SRM, which requires snow cover as a driving variable. The method used by the SRM for calculating the snow cover in a new climate is described. Results of generating year-round hydrographs in a new climate $\left(+4^{\circ} \mathrm{C}\right)$ are presented for a near-normal runoff year. A new radiation-based version of the SRM is also described. The potential for using the radiation version to evaluate not only the effects of changed temperature and precipitation but changed humidity and cloudiness is discussed. An example of the effects of changing cloud optical thickness on the discharge hydrograph is given.

\section{ACKNOWLEDGEMENTS}

Special thanks are given toJ. Martinec and K. Brubaker for 
their assistance in developing the SRM climate-change hydrographs. R. Roberts has programmed the climate-change and radiation versions of the SRM. J. Kim developed the figures presented.

\section{REFERENCES}

Becker, A. and P. Serban. 1990. Hydrological models for water-resources system design and hydrological models for water-resources system design and operation. Geneva, World Meteorological Organization. (Operational Hydrology Report 34.

Blöschl, G., R. Kirnbauer and D. Gutknecht. 1991. Distributed snowmelt simulations in an Alpine catchment. I. Model evaluation on the basis of snow cover patterns. Water Resour. Res., 27 (12), 3171-3179.

Brandt, M. and S. Bergström. 1994. Integration of field data into operational snowmelt-runoff models. Nord. Hydrol., 25 (1-2), 101-112.

Brubaker, K. and A. Rango. 1996. Response of snowmelt hydrology to climate change. Water, Air, Soil Pollut., 41 (4), 335-343

Brubaker, K., A. Rango and W. Kustas. 1996. Incorporating radiation inputs into the snowmelt runoff model. Hydrol. Processes, 10 (10), 1329-1343.

Carroll, T. R. 1995. Washington, DC, National Aeronautics and Space Administration, 3-14. (NASA CP-3318.)

Cooley, K. R. 1990. Effects of $\mathrm{CO}_{2}$ induced climatic changes on snowpack and streamflow. Hydrol. Sci. J., 35 (5), 511-522.

Foster, J. L. and A. Rango. 1982. Snow cover conditions in the Northern Hemisphere during the winter of 1981. f. Climatol, 2 (1), 171-183.

Gleick, P. H. 1989. Climate change, hydrology, and water resources. Rev. Geophys., 27 (3), 329-344.

Goodell, B. C. 1966. Snowpack management for optimum water benefits. ASCE Water Resources Engineering Conference. New York, American Society of Civil Engineers (Preprint 379.)

Kirnbauer, R., G. Blöschl and D. Gutknecht. 1994. Entering the era of distributed snow models. Nord. Hydrol., 25 (1-2), 1-24.

Kite, G.W. 1993. Application of a land class hydrological model to climate change. Water Resour. Res., 29 (7), 2377-2384.

Kite, G.W. 1995. The SLURP model. In Singh, V. P., ed. Computer models of watershed hydrology. Highlands Ranch, CO, Water Resources Publications, $521-562$.
Kustas, W. P., A. Rango and R. Uijlenhoet. 1994. A simple energy budget algorithm for the snowmelt runoff model. Water Resour. Res., 30 (5), 1515- 1527.

Leavesley, G. H. and L. G. Stannard. 1990. Application of remotely sensed data in a distributed-parameter watershed model. In Kite, G.W. and A. Wankiewicz, eds. Proceedings of the Workshop on Applications of Remote Sensing in Hydrology, 13-14 February 1990, Saskatoon, Saskatchewan. Saskatoon, Sask., Environment Canada. National Hydrology Research Institute, 47-64. (NHRI Symposium 5.)

Martinec, J. 1985. Snowmelt runoff models for operational forecasts. Nord. Hydrol., 16 (3), 129-136.

Martinec, J. and A. Rango. 1987. Interpretation and utilization of areal snow-cover data from satellites. Ann. Glaciol., 9, 166-169.

Martinec, J., A. Rango and R. Roberts. 1994. Snowmelt runoff model (SRM) users manual. Geographica Bernesia 29.

Nash, L. L. and P. H. Gleick. 1993. The Colorado River basin and climate change. Washington, DC, U.S. Environmental Protection Agency. Pacific Institute for Studies in Development, Environment and Security, Oakland, CA. (EPA Report 230-R-93-009.)

Pangoulia, D. 1991. Hydrological response of a medium-sized mountainous catchment to climatic changes. Hydrol, Sci. J., 36 (6), 52.5-547.

Rango, A. 1992. Worldwide testing of the snowmelt runoff model with applications for predicting the effects of climate change. Nord. Hydrol., 23 (3), $155-172$.

Rango, A. and M. Baumgartner. 1996. Data transfer, necessary interfaces, and applications in a modular snow hydrology modeling system. In Singhroy, V. H., D. Nebert and A. I. Johnson, eds. Remole sensing and GIS for site characterization: applications and standards. San Francisco, CA, American Society for Testing and Materials, 38 - 42. (ASTM STP 1279.)

Simpson, J. J. and J. L. Gobat. 1995. Improved cloud detection in GOES scenes over land. Remote Sensing Environ., 52 (1), 36 - 54.

Steppuhn, H. 1981. Snow and agriculture. In Gray, D. M. and D. H. Male, eds. Handbook of snow: principles, processes, management, and use. New York, etc., Pergamon Press, 60-125.

Van Katwijk, V. F., A. Rango and A. E. Childress. 1993. Effect of simulated climate change on snowmelt runoff modeling in selected basins. Water Resour. Bull., 29(5), 755-766.

Wielicki, B. A., B. R. Barkstrom, E. F. Harrison, R. B. Lee, III, G. L. Smith and J. L. Cooper. 1996. Clouds and the Earth's radiant energy system (CERES): an Earth observing system experiment. Bull. Am. Meteorol. Soc, $77(5), 853-868$. 